\title{
OPTIMAL CHOICE OF ACETYLCHOLINESTERASE REACTIVATORS FOR ANTIDOTAL TREATMENT OF NERVE AGENT INTOXICATION
}

\begin{abstract}
Jiři Bajgar
University of Defence in Brno, Faculty of Military Health Sciences in Hradec Králové, Czech Republic: Department of Toxicology

Summary: The studies dealing with mechanism of organophosphates (OP)/nerve agent action, prophylaxis and treatment of intoxications is a very hot topic at present. Though the research is very intensive, unfortunately, up to now, there is not universal or significantly better reactivator sufficiently effective against all nerve agents/OP when compared with presently available oximes (pralidoxime, methoxime, obidoxime, trimedoxime, HI-6). The use of the most effective reactivator (HI-6) using simple type of autoinjector (e.g. ComboPen) is strictly limited because of decomposition of HI-6 in solution. Thanks to better solubility it is clear that another salt of HI-6 (dimethanesulfonate, HI-6 DMS) is more convenient for the use as antidote against nerve agents in the autoinjector than $\mathrm{HI}-6$ chloride $(\mathrm{Cl})$. It was clearly demonstrated that reactivation potency of HI-6 DMS in comparison with HI-6 Cl in vivo was the same and bioavailability of HI-6 DMS is better than that of HI-6 Cl. Three chambered autoinjector allows administration of all three antidotes (atropine, reactivator, diazepam) simultaneously. Moreover, the content of chambers can be changed according to proposed requirements. Possible way to solve the problem of universal reactivator could be the use of two reactivators. Three chambered autoinjector is an ideal device for this purpose.
\end{abstract}

Key words: Anticholinergics; Reactivators; Nerve agents; Acetylcholinesterase; Treatment

\section{Introduction}

Very important chemicals in the group of organophosphates (OP) are inhibitors of cholinesterases. These compounds are used in industry, in veterinary or human medicine and, last but not least, these agents are, unfortunately, usable (and used) for military purposes as chemical warfare agents (nerve agents), and as poisons used by terrorists as it was documented in Japan $(1994,1995)$. The broadest spectrum of these compounds is used as pesticides (insecticides), acaricides etc. According to the World Health Organization, more than one million serious accidental and two million suicidal poisonings with insecticides occur worldwide every year, and of these approximately 200,000 die, mostly in developing countries $(1,3,15)$. Thus, the studies dealing with mechanism of $\mathrm{OP} /$ nerve agent action, prophylaxis and treatment of intoxications is a very hot topic at present.

The basic mechanism of toxic effects induced by nerve agents involves the inhibition of cholinesterases, in particular acetylcholinesterase (AChE, EC 3.1.1.7) in the central and peripheral nervous system. The resulting accumulation of acetylcholine at the synaptic junctions desensitizes the cholinergic receptor sites, and symptoms of intoxication are developed $(1,13,16,29,37,47)$. Dominating signs of poisoning with OP and nerve agents are caused by hyperstimulation of the cholinergic nervous system caused by AChE inhibition (acute cholinergic crisis), characterized by convulsions, disturbed ventilation and metabolic dysbalance. According to type and localization, peripheral and central muscarinic and nicotinic symptoms are observed (1). Very simple scheme of nerve agent intoxication and its treatment is given in Fig. 1. The action of nerve agents is very fast and, therefore, the first aid is of great importance. Quick and easy injection of antidotes is necessary to increase a probability of life saving. The devices solving automatic administration of drugs by injection - autoinjectors were developed in the in 1951 (Atropen) in the United States, followed by others autoinjectors in many armies for the first aid in case of nerve agent exposure (38).

The principle of $\mathrm{AChE}$ inhibition is phosphorylation (phosphonylation) of the serine group on the catalytic triade (active center) of AChE. The rate of spontaneous dephosphorylation is very low and it can be omitted in most cases. However, it can be improved/increased using cholinesterase reactivators (oximes) able to reactivate nerve agent-inhibited AChE. These compounds with an ionized oxime group will break the bond between $\mathrm{AChE}$ and $\mathrm{OP}$ and re- 


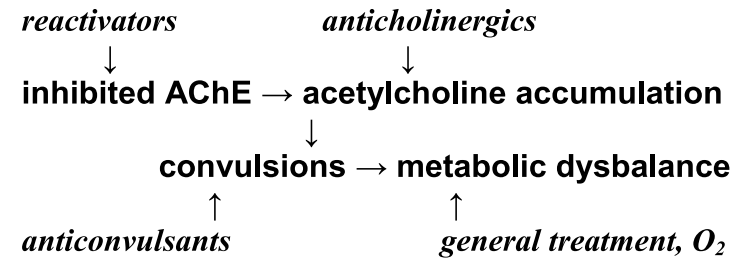

Fig 1: Simplified scheme of action of nerve agents and possible therapeutic countermeasures (in italics).

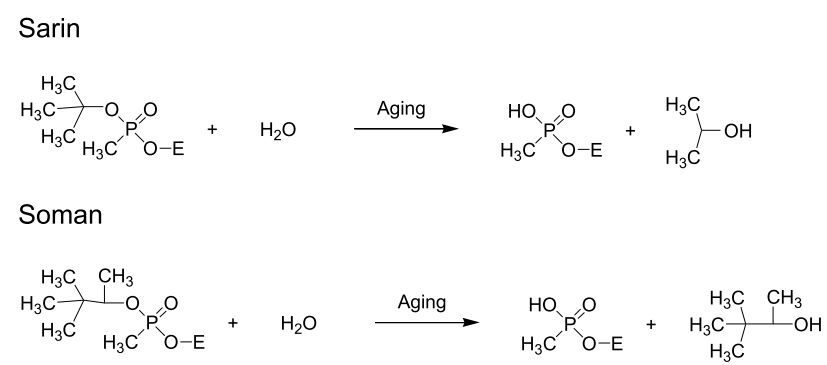

Fig. 2: Scheme of dealkylation (aging) of AChE (represented by E) inhibited by sarin and soman.

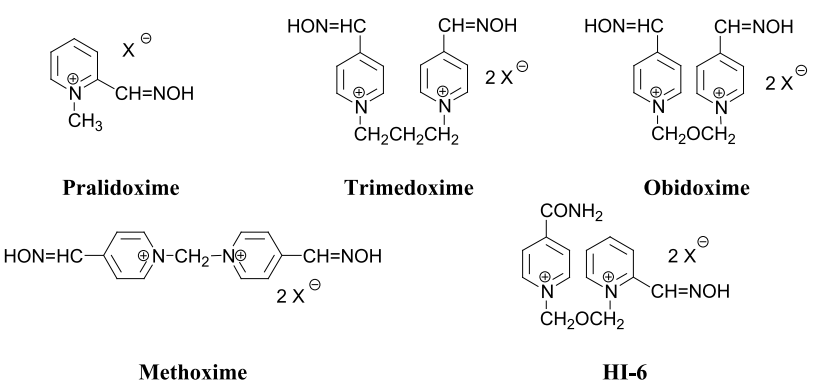

Fig. 3: Chemical structures of commercially available AChE reactivators.

store enzyme activity (reactivation) by the nucleophilic attack on phosphorylated or phosphonylated serine at the active center of the AChE molecule and liberate the free enzyme (1). This fact is limiting factor for the therapy with reactivators. The rest of the nerve agent forms a complex with the reactivator (more toxic but less stable) hydrolyzing practically immediately and not having high importance for the course of intoxication (1). The efficacy of oxime reactivation is dependent on both oxime and the conjugated phosphonate structure $(1,33)$. Simultaneously, the microenvironment of the gorge plays a significant role in determining the selectivity of the substrate and inhibitors for cholinesterases. Depending on the structure of the inhibitor, inhibited AChE is dealkylated (aged) and the complex formed is resistant to the reactivation effect. The molecular mechanism is explained by the splitting of the complex forming the alcohol and unreactivatable enzyme (Fig. 2). This reaction, called aging or dealkylation is very fast for so- man-inhibited AChE (the half-life is about $10 \mathrm{~min}$ ) and it is less expressed for sarin (the half-life is about 10 hours), for VX-inhibited AChE this reaction was not observed within 24 hours $(1,33)$. This is one of the reasons for difficult therapeutic interventions of soman intoxication $(1,24,33,37)$.

The fate of poisoned organism is very dependent on early administered antidotes. Based on our knowledge of the mechanism of action, two therapeutic principles for antidotal treatment are used. The main drugs are anticholinergics (preferably atropine), that antagonize the effects of accumulated acetylcholine at the cholinergic synapses (also called symptomatic antidotes) and cholinesterase reactivators (oximes) to reactivate inhibited $\mathrm{AChE}$ (causal antidotes) $(1,13,14,37)$. Their effects are synergistic. Benzodiazepines are also used to treat convulsions (anticonvulsants, usually diazepam) (1,42). Treatment of metabolic dysbalance, ions hypoequilibrium and support of vital functions (heart, ventilation) is necessary. The use of atropine is without any discussion; other anticholinergics may be even more efficacious. The centrally acting anticholinergics (benactyzine, biperidene) can be very useful in therapy of soman poisoning $(1,20,22)$. Anticonvulsants (diazepam) in the treatment of $\mathrm{OP} /$ nerve agent poisoning are also frequently used $(1,27,29)$. However, the use of reactivators is more complicated question.

\section{The choice of reactivators}

The choice of reactivators is not so simple $(17,24,33$, 34,39). Their administration alone is not effective but simultaneous administration with atropine potentiates their antidotal effects based on AChE reactivation at the cholinergic nerve synapses. AChE reactivation at the peripheral nervous system is indisputable; however, their passing the blood-brain-barrier facilitating their central reactivation efficacy in vivo was demonstrated $(2,3,26-28)$. Though the research is very intensive, unfortunately, up to now, there is not universal or significantly better reactivator sufficiently effective against all nerve agents/OP when compared with presently available oximes $(19,31,33,41)$.

As it was described many times, there are only few commercially available AChE reactivators on the market pralidoxime (2-PAM; P2S; 2-hydroxyiminomethyl-1-methylpyri-dinium chloride or methansulphonate), trimedoxime (Fosan ${ }^{\circledR}, 1,3$-bis(4-hydroxyiminomethylpyridinium)-propane dichloride or dibromide), obidoxime (Toxogonin ${ }^{\circledR}$; LüH-6; 1,3-bis(4-hydroxyiminomethylpyridinium)-2-oxapropane dichloride), methoxime (MMC-4; MMB-4; 1,1-bis(4hydroxyiminomethylpyridinium)-methane dichloride or dibromide) and HI-6 (1-(2-hydroxyiminomethylpyridinium) -3-(4-carbamoylpyridinium)-2-oxapropane dichloride or dimethanesulfonate) (Fig. 3). Unfortunately, none of them is able to reactivate $\mathrm{AChE}$ inhibited by all nerve agents and OP pesticides $(19,31,33,40,41)$. Due to fast dealkylation of AChE inhibited by soman (aging), treatment of soman intoxication using reactivators seems to be a special problem. 
For example, pralidoxime, the gold standard of AChE reactivators, is from the historical point of view the most used AChE reactivator. However, potency of pralidoxime to reactivate tabun-, cyclosarin-, soman- or pesticide-inhibited $\mathrm{AChE}$ is poor (31). This is probably the reason for replacement of pralidoxime in the US Army by methoxime. In the literature, its use during pesticide poisoning was discussed many times. Consequently, its reactivation results are controversial $(14,24,45)$. If pesticides are discussed, obidoxime and trimedoxime are the most promising reactivators $(40,44)$. However, their potencies to reactivate cyclosarinand soman-inhibited AChE are not good enough (33). If tabun-inhibited $\mathrm{AChE}$ reactivation is discussed, these reactivators are promising compared with other commercially available ones $(5,8,9,10,25)$. On the contrary, their reactivation potency is generally not sufficient as it is expected for promising oximes. Other currently available oxime on the market - methoxime - seems to be very promising in case of cyclosarin, sarin and VX poisoning (31). Its potency to reactivate tabun-, soman- and pesticides-poisoning is poor (33). The most promising oxime of commercially available ones is H-oxime HI-6. In view of military purposes (e.g. antidote against nerve agents), it is able to reactivate almost all nerve agent-inhibited AChE with exception of tabun (31). On the contrary, if civilian importance is considered, HI-6 is unable to reactivate $\mathrm{AChE}$ in case of $\mathrm{OP}$ pesticide- poisoning (31, 43). From this short summarization of antidotal effect of reactivators against nerve agent/OP poisoning is clear that there are relatively effective oximes (trimedoxime, obidoxime, methoxime) but the most effective seems to be the oxime HI-6. These observations are supported by extensive reviews dealing with the topics mentioned $(1,13,24,31,33,36)$.

In conclusion, action of reactivators as non replaceable part of antidotal therapy against OP/nerve agents intoxication is based on AChE reactivation in the different structures of the nervous system. The HI- 6 appears to be very promising antidote against nerve agents including soman.

There are another oximes slightly better than HI-6 (e.g. HLö-7) but preclinical and clinical research to be done for their permission and involvement into medical practice is expensive and final result (as therapeutic effectiveness) is not sufficient $(11,21)$. The same can be applied for oximes K-048, K201 etc. $(27,33,34,41)$. As it was mentioned before, the action of OP (and, especially nerve agents) is very fast and, therefore, the first aid is necessary as quick as possible. Automatic administration of antidotes is solved by the use of autoinjector, however, the question of content (effective antidotes) of autoinjector is more complicated.

At present, generally two types of autoinjectors (with atropine and reactivator) are mostly used, i.e. ComboPen containing atropine and obidoxime in one solution; it is the first choice. However, the use of more effective reactivator (HI-6) using this type of autoinjector is strictly limited because of decomposition of HI-6 in solution. This situation can be solved using wet/dry (two chambered) autoinjector containing in its chamber solution of atropine and in the se- cond one reactivator HI-6 in powdered (lyophilized) form (HI-6 chloride). They are produced by ASTRA (Sweden) and STI (USA) $(1,7,38)$.

\section{Clinical use of HI-6}

There is only limited experience in human posioning by highly toxic $\mathrm{OP} /$ nerve agents but it is generally accepted that the persistence of clinically relevant amounts of nerve agent in blood is shorter than that of OP. However, as a result of the nerve agent-inhibited $\mathrm{AChE}$, which may be very rapid following poisoning with soman, it is suggested that in the absence of clinical improvement, administration of oxime for periods in excess of 24-48 hours is unlikely to achieve further reactivating of the enzyme (for review, see, e.g. 1,14,15,36). Other studies were performed: double blind placebo controlled clinical studies of pharmacokinetics and tolerance of HI-6 administered i.m. to healthy volunteers (in combinations with atropine $2 \mathrm{mg}$ ) published by Clement et al. (12) and Kusic et al. (35) (blood levels, urinary excretiona and tolerance) showed that changes observed following HI-6 treatment were not clinically important (44). Therapeutic effect of HI-6 as antidote against malathion and mevinfos was described Jovanovic et al. (18). Moreover, HI-6 is involved in the equipment of the Czech, Slovak, Swedish and Canadian Armies as antidote against nerve agent intoxication.

\section{Different salts of HI-6}

HI-6 in autoinjectors is used as a chloride salt. Its physical chemical properties are sufficient but there are other salts of HI-6 having these properties (especially the solubility) better than chloride as described by Kuca et al. (32): twelwe salts of HI-6 were tested for solubility in water, saline and saline with atropine at different conditions (temperature) $-3,5^{\circ} \mathrm{C}$ (winter condition), $25^{\circ} \mathrm{C}$ (Europe condition), and $40{ }^{\circ} \mathrm{C}$ (dessert condition), respectively. The solubility of HI-6 dimethanesulfonate (HI-6 DMS) was much more better in comparison with HI-6 chloride; this property is very useful for the use of HI-6 DMS in the autoinjector. Better solubility predicts better bioavailability and simultaneously, better evaluation of the whole content of oxime in the autoinjector. Reactivation potency of HI-6 chloride and HI-6 DMS against by nerve agent inhibited AChE in vitro was the same $(30,32)$. Simultaneously, it was clearly demonstrated that reactivation potency of HI-6 DMS in comparison with HI-6 chloride in vivo was the same or better $(27,28)$. Thus, thanks to better solubility it is clear that HI-6 DMS is more convenient for the use as antidote aginst nerve agents in the autoinjector.

\section{Two- or three-chambered autoinjector}

Practical use of antidotes in the automatic devices is limited by a stability of the drug in solution contained in the autoinjector. Two autoinjectors for the first aid against 
nerve agents are used in different armies - autoinjector containing atropine and reactivator (usually obidoxime) and the autoinjector with diazepam. It appears from previous analysis, obidoxime is not optimal antidote (reactivator) but the use of better oxime - HI-6 - can not be applicable because of low stability of HI-6 in solution. For the use of HI-6, two chambered autoinjector is necessary using dichloride salt of HI-6; however, its solubility is not optimal. In all cases, it is one device for the soldier; the second one is the other autoinjector for diazepam administration. Thus, two administrations (and two manipulations) are necessary for the first aid. An idea of three-chambered autoinjector is more interesting: the content of three-chambered autoinjector is atropine in solution, the best reactivator HI- 6 as a lyphilized powder and diazepam in solution. Stated differently, for administration of all types of antidotes using three-chambered autoinjector, one manipulation only is needed. Moreover, the content of chambers can be changed according to proposed requirements, e.g. adding of new anticholinergic drug like benactyzine or akineton, centrally acting anticholinergic drugs with good antidotal effect against nerve agents such as soman (1,20-23). It is not excluded the change of the chamber content by quite another drugs such as other benzodiazepines (e.g. midazolam), analgetics, antiemetics or other reactivators according to customer request. In connection with nerve agent intoxication (especially tabun exposure), the autoinjector can be used also for prophylaxis, either with classic prophylactics described $(3,6)$ or new ones, e.g. huperzine A $(4)$; simultaneously it could be of interest to replace diazepam with another reactivator: as it was mentioned before, universal reactivatot (up to now) is not known. They were some attempts to solve this problem using two oximes differently reactivating $\mathrm{AChE}$ inhibited by various nerve agents. It is known that HI-6 is not very effective against tabun and OP insecticides; on the other hand, obidoxime or trimedoxime are effective against tabun and OP insecticides.

Effects of combination of two reactivators were described: this approach was tested in vitro with obidoxime and HI-6 on AChE inhibited by tabun; it was demonstrated that reactivating effect is due to the effective oxime (i.e. obidoxime in case of tabun inhibited $\mathrm{AChE}$ ) and combination of obidoxime with HI-6 copied the effect of obidoxime alone (46). Similar combination (HI-6 and trimedoxime) was tested in rats; it was concluded that the $\mathrm{AChE}$ reactivation in vivo is not a summation (or simple copying) of the effect of more effective oxime but more probably, it is a potentiation of the effect of both reactivators $(5,8)$. Therefore, possible way to solve the problem of universal reactivator could be the use of two reactivators. Three chambered autoinjector is an ideal device for this purpose $(7,34)$.

\section{Conclusions}

- At present, HI-6 can be considered as optimal reactivator for the treatment of nerve agents intoxication.
- Following administration of HI-6 to healthy volunteers, the changes observed are not of clinical importance.

- HI-6 dimethanesulfonate (lyophilized form) is more suitable for the use in the autoinjector than HI-6 dichloride.

- Three-chambered autoinjector can be considered as the optimal device for administration of antidotes against nerve agent intoxication

\section{Acknowledgement}

This work was supported by the Grant of the Ministry of Defence (FVZ 0000501).

\section{References}

1. Bajgar J. Organophosphates/nerve agent poisoning: mechanism of action, diagnosis, prophylaxis and treatment. Adv.Clin.Chem. 2004; 38: 151-216.

2. Bajgar J, Fusek J, Kuca K, Bartosova L, Jun D. Treatment of organophosphate intoxication using cholinesterase reactivators: facts and fiction. Mini-Rev. Med. Chem. 2007; 7: 461-466.

3. Bajgar J, Kuca K, Jun D, Bartosova L, Fusek J. Cholinesterase reactivators: the fate and effects in the organism poisoned with organophosphates/nerve agents. Curr. Drug Metab. 2007; 8: 803-809.

4. Bajgar J, Hajek P, Karasova J, Slizova D, Krs O, Kuca K, Jun D, Fusek J, Capek L. Inhibition of acetylcholinesterase in different structures of the rat brain following soman intoxication pretreated with Huperzine A. Int. J. Mol. Sci. 2007; 8: $1165-1176$.

5. Bajgar J. Treament and prophylaxis of nerve agent/organophosphates intoxication. Therap. Pharmacol. Clin. Toxicol. 2009; 13: 247-253.

6. Bajgar J, Fusek J, Kassa J, Kuca K, Jun D. Pharmacological prophylaxis against nerve agent poisoning: experimental studies and practical implications, Chapter 64. In: Handbook of Toxicology of Chemical Warfare Agents (R.C. Gupta, Ed.), Elsevier - Academic Press, 2009, pp. 877-885.

7. Bajgar J. Development of antidotes against nerve agents in the Czech Republic. ASA Newslett. 2009; 09-8: 7-9.

8. Bajgar J, Zdarova Karasova J, Kassa J, Cabal J, Fusek J, Blaha V, Tesarova V. Tabun-inhibited rat tissue and blood cholinesterases and their reactivation with the combination of trimedoxime and HI-6 in vivo. Chem.-Biol. Interact. 2010; 187:287-290.

9. Cabal J, Kuca K, Kassa J. Specification of the structure of oximes able to reactivate tabun-inhibited acetylcholinesterase. Basic Clin. Pharmacol. Toxicol. 2004; 95: $81-86$.

10. Calic M, Lucic-Vrdoljak A, Radic B, Jelic D, Jun D, Kuca K, Kovarik Z. In vitro and in vivo evaluation of pyridinium oximes: mode of interaction with acetylcholinesterase, effect on tabun- and soman-poisoned mice and their cytotoxicity. Toxicology 2006; 219: 85-96.

11. Clement JG, Hansen AS, Boulet CA. Efficacy of HLö-7 and pyrimidoxime as antidotes of nerve agent poisoning in mice. Arch. Toxicol. 1992; 66: 216-219.

12. Clement JG, Bailey DG, Madill HD, Tran LT, Spence JD. The acetylcholinesterase oxime reactivator in man: pharmacokinetics and tolerability in combination with atropine. Biopharm. Drug Dispos. 1995; 6: 415-425.

13. Delfino RT, Ribeiro TS, Figueroa-Villar JD. Organophosphorus compounds as chemical warfare agents: a review. J. Braz. Chem. Soc., 2009; 20: 407-428.

14. Eddleston M, Eyer P, Worek F, Mohamed F, Senarathna L, von Mayer L, Juszczak E, Hittarage A, Azhar S, Dissanayake W, Rezvi Sheriff MH, Szinicz L, Dawson AH, Buckley NA. Differences between organophosphorus insecticides in human self-poisoning: a prospective cohort study. Lancet 2005; 366: $1452-1459$.

15. Eyer P. The role of oximes in the menagement of organophosphorus pesticide poisoning. Toxicol. Rev. 2003; 22: 165-190.

16. Fusek J, Bajgar J, Kassa J, Hajek P, Slizova D, Krs O. Differences in the action of G- and V-agents, Chapter 2. In: Central and peripheral nervous system: effects of highly toxic organophosphates and their antidotes (J. Bajgar, Ed.), Research Signpost, Kerala, 2009, pp. 9-17.

17. Jokanovic M, Prostran M. Pyridinium oximes as cholinesterase reactivators. Structure-activity relationship and efficacy in the treatment of poisoning with organophosphorus compounds. Curr. Med. Chem. 2009; 16: 2177-2188.

18. Jovanovic D, Randelovic S, Joksovic D, Todorovic V. Farmakokinetika oksima HI-6 u bolesnika sa akutnim trovanijem organofosfornim insekticidina. Vojnosanit. Pregl. 1993; 50: 27-31.

19. Kalasz HJ, Furész J, Tekes K. Monitoring the pharmacokinetics of pyridinium aldoximes in the body. Mini-Rev. Med. Chem. 2009; 9: 448-446.

20. Kassa J, Frankova K, Hoder P, Patocka J. A comparison of the efficacy ofcholinolytics atropine and biperiden (Akineton) in combination with HI-6 on cholinergic and stressogenic effects of soman in rats. Homeostasis 1996; 37: 135-136. 
21. Kassa J, Cabal J. A comparison of the efficacy of a new asymmetric bispyridinium oxime $\mathrm{BI}-6$ with currently available oximes and $\mathrm{H}$ oximes against soman by in vitro and in vivo methods. Toxicology 1999; 132: 111-118.

22. Kassa J, Vachek J, Bajgar J, Fusek J. A combination of pyridostigmine with anticholinergic drugs: effective pharmacological pretreatment of soman-poisoned mice. ASA Newslett. 2001; 84: 16-19.

23. Kassa J, Vachek J, Bajgar J, Fusek J. A comparison of the efficacy of pharmacological pretreatments against soman in mice. Voj. Zdrav. Listy 2001; 70 (Suppl): $22-25$.

24. Kassa J. Review of oximes in the antidotal treatment of poisoning by organophosphorus nerve agents. J. Toxicol. Clin. Toxicol. 2002; 40: 803-816.

25. Kassa J, Kuca K, Cabal J. Comparison of the efficacy of currently available oximes against tabun in rats. Biologia 2005; 60/Suppl.: 77-79.

26. Kassa J, Kuca K, Cabal J, Paar M. A comparison of the efficacy of new asymmetric bispyridinium oximes (K027, K048) with currently available oximes against tabun by in vivo methods. J. Toxicol. Environm. Hlth. 2006, part A; 69: $1875-1882$.

27. Kassa J, Kuca K, Karasova J, Musilek K, Jun D, Bajgar J, Cabal J, Stetina R, Fusek J. Development of new reactivators of tabun inhibited acetylcholinesterase and the evaluation of thein efficacy by in vitro and in vivo methods. HFM-149 Symposium on "Defense against the effects of chemical toxic hazards: Toxicology, diagnosis and medical Countermeasures”. Edinburgh, Scotland (GBR), 8-10 October 2007. Session 4, OP Medical Countermeasures, No 17.

28. Kassa J, Jun D, Kuca K, Bajgar J. Comparison of reactivating and therapeutic efficacy of two salts of the oxime HI-6 against tabun, soman and cyclosarin in rats. Bas. Clin. Pharmacol. Toxicol. 2007; 101: 328-332.

29. Kassa J, Bajgar J, Fusek J. Efects of nerve agents, Chapter 1. In: Central and peripheral nervous system: effects of highly toxic organophosphates and their antidotes (J. Bajgar, Ed.), Research Signpost, Kerala, 2009, pp. 1-8.

30. Kuca K, Cabal J, Kassa J. In vitro reactivation of sarin-inhibited brain acetylcholinesterase from various species by various oximes. J. Enz. Inh. Med. Chem. 2005; 20: 227-232.

31. Kuca K, Jun D, Bajgar J. Structural factors influencing potency of currently used acetylcholinesterase reactivators for treatment of cyclosarin intoxications. Curr. Pharm. Design 2007: 13: 3445-3452.

32. Kuca K, Musilek K, Stodulka P, Marek J, Hanusova P, Jun D, Hrabinova M, Kassa J, Dolezal B. Twelve different HI-6 salts and their potency to reactivate cyclosarin inhibited AChE in vitro. Lett. Drug Des. Discov. 2007; 4: 510-512.

33. Kuca K, Musilek K, Jun D, Bajgar J, Kassa J. Novel oximes, Chapter 66. In Handbook of Toxicology of Chemical Warfare Agents (R.C. Gupta, Ed.), Elsevier - Academic Press, 2009, pp. 997-1021.

34. Kuca K, Jun D, Kassa J, Marek J, Stodulka P, Musilek K, Dolezal B, Povraznik
J. Development of new Czech autoinjector with oxime HI-6 DMS. CBMTS Industry, Dubrovnik (Croatia), 5-10 April 2009.

35. Kusic R, Boskovic B, Vojvodic V, Jovanovic D. HI-6 in man: blood levels, urinary excretion, and tolerance after intramuscular administration of the oxime to healthy volunteers. Fund. Appl. Toxicol. 1985; 5: S89-S97.

36. Lundy PM, Raveh L, Amitai G. Development of the bisquaternary oxime HI-6 toward clinical use in the treatment of organophosphate nerve agent poisoning. Toxicol. Rev. 2006; 25: 231-243.

37. Marrs T, Maynard RL, Sidell FR. Chemical warfare agents - toxicology and treatment, John Wiley \& Sons, 1996, pp. 83-113.

38. Mesa M. From battlefield to backpack: evolution of the Auto-injector. ASA Newslett. 2010; 10-1: 15-18.

39. Milatovic D, Jokanovic M. Pyridinium oximes as cholinesterase reactivators in the treatment of OP poisoning, Chapter 65. In: Handbook of Toxicology of Chemical Warfare Agents (R.C. Gupta, Ed.), Elsevier - Academic Press, 2009, pp. 985-996.

40. Musilek K, Kuca K, Jun D, Dohnal V, Dolezal M. Synthesis of a novel series of bispyridinium compounds bearing a xylene linker and evaluation of their reactivation activity against chlorpyrifos-inhibited acetylcholinesterase J. Enzyme Inhib. Med. Chem. 2005; 20: 409-415,

41. Musilek K, Jun D, Cabal J. Kassa J, Gunn-More F, Kuca K. Design of a potent reactivator of tabun-inhibited acetylcholinesterase - synthesis and evaluation of (E)-1-(4-carbamoylpyridinium)-4-(4-hydroxyiminomethylpyridinium)-but-2-ene dibromide (K203). J. Med. Chem. 2007; 50: 5514-5518.

42. Myhrer T. Prophylactic and therapeutic measures in nerve agent poisoning, Chapter 63. In: Handbook of Toxicology of Chemical Warfare Agents (R.C. Gupta, Ed.), Elsevier - Academic Press, 2009, pp. 965-973.

43. Petroianu GA, Arafat K, Nurulain SM, Kuca K, Kassa J. In vitro oxime reactivation of red blood cell acetylcholinesterase inhibited by methyl-paraoxon. J. Appl. Toxicol. 2007: 27: 168-175.

44. Thiermann H, Mast U, Klimmek R, Eyer P, Hibler A, Pfab R, Felgenhauer N, Zilker T. Cholinesterase status, pharmacokinetics and laboratory findings during obidoxime therapy in organophosphate poisoned patients. Hum. Exp. Toxicol. 1997; 16: 473-480.

45. Worek F, Diepold C, Eyer P. Dimethylphosphoryl-inhibited human cholinesterases: inhibition, reactivation, and aging kinetics Arch. Toxicol. 1999; 73: 7-14.

46. Worek F, Aurbek N, Thiermann H. Reactivation of organophosphate-inhibited human AChE by combinations of obidoxime and HI-6 in vitro. J. Appl. Toxicol. 2007; 27: 582-588.

47. Wright L, Pope C, Liu J. The nervous system, as a target for chemical warfare agents, Chapter 32. In: Handbook of Toxicology of Chemical Warfare Agents (R.C. Gupta, Ed.), Elsevier - Academic Press, 2009, pp. 463-480.

Received: $14 / 06 / 2010$.

Accepted: 02/07/2010.

\section{Corresponding author:}

Doc. MUDr. Jiří Bajgar, DrSc., Department of Toxicology, Faculty of Military Health, Sciences, Třebešská 1575, 50001 Hradec Králové, Czech Republic; e-mail: bajgar@pmfhk.cz 